\title{
Chinese Medicine for Chronic Obstructive Pulmonary Disease: A Pilot Study on Patient Preferences
}

\author{
Shaonan Liu' \\ Jiaqi Lai $\mathbb{D}^{\prime}$ \\ Lei $\mathrm{Wu}^{2}$ \\ Xinfeng Guo'
}

'Evidence-based Medicine \& Clinical Research Service Group, The Second Affiliated Hospital of Guangzhou University of Chinese Medicine (Guangdong Provincial Hospital of Chinese Medicine), Guangzhou, Guangdong Province, People's Republic of China; ${ }^{2}$ Respiratory Department, The Second Affiliated Hospital of Guangzhou University of Chinese Medicine (Guangdong Provincial Hospital of Chinese Medicine), Guangzhou, Guangdong Province, People's Republic of China
Correspondence: Xinfeng Guo Evidence-based Medicine \& Clinical Research Service Group, The Second Affiliated Hospital of Guangzhou University of Chinese Medicine (Guangdong Provincial Hospital of Chinese Medicine), No. II I, Dade Road, Guangzhou, People's Republic of China, 510120

Tel +86|3678906862

Email guoxinfeng@gzucm.edu.cn
Purpose: The patient's preference plays an important role in clinical practice. There currently is no available evidence regarding the perception and attitudes of patients with chronic obstructive pulmonary disease (COPD) towards the use of Chinese medicine (CM) approaches. This study was designed to explore preferences and factors associated with $\mathrm{CM}$ among COPD patients.

Patients and Methods: A pilot survey was conducted among COPD patients using a structured, pre-tested questionnaire. The perceptions of $\mathrm{CM}$ therapies (including herbal medicine, non-pharmacotherapies), and expected clinical outcomes were investigated based on patient preference. Factors associated with preference of treatment scenarios were estimated in order of importance.

Results: Thirty patients were enrolled in the survey, including 27 males and 3 females. Twothirds of the patients preferred integrative Chinese and Western medicine for the treatment of COPD. Chinese patent medicines and CM decoction therapy were more popular than CM injections. The preferred non-drug therapy was point application, followed by acupuncture, Tai chi, or Qigong. More than $70 \%$ of patients reported that important clinical outcomes were improvements in lung function (77\%) and dyspnea, cough, and sputum symptoms $(73 \%)$, followed by exercise endurance (50\%). Besides clinical efficacy, costs and side effects were also important factors for treatment selection.

Conclusion: This pilot study showed that Chinese patent medicine and CM decoctions were preferred options for complementary medicines to combine with routine pharmacotherapy for COPD treatment according to the patients' preferences. The improvement of dyspnea, cough symptoms, and lung function was the most desired clinical outcomes for patients. Quicker symptom relief, lower costs, and fewer side effects were key attributes for the treatment selection. Further research with a larger sample size is needed to definitively address the comprehensive conclusion.

Keywords: patient preference, Chinese medicine, COPD

\section{Introduction}

Chronic obstructive pulmonary disease (COPD) is a serious public health concern and a cause of severe morbidity and mortality worldwide. Despite the number of recommended effective treatment regimens to manage COPD, treatment outcomes are negatively influenced by the low level of adherence to treatment. ${ }^{1,2}$ Almost $60 \%$ patients with COPD have been reported not adhere to medicines. ${ }^{3,4}$ Reasons for non-adherence to COPD treatment are complex and are affected by numerous factors including perceptions of patients and physicians, and social status. ${ }^{5}$ 
Patient preference, experience, and understanding of COPD treatment have been shown to be critical for medication adherence. ${ }^{6}$

As a broad term, values and preferences are usually influenced by a patient's perspectives, priorities, beliefs, expectations, and goals for health and lifestyle. ${ }^{7}$ More precisely, the selection of a treatment option is based on an individual's preference and reflects the potential benefits, adverse effects, costs, and inconvenience compared with available alternatives. ${ }^{8}$ Evidence-based medicine requires that the value and preferences of patients should be integrated into clinical decision-making processes. To date, several studies have explored patient preferences for COPD, ${ }^{9-11}$ especially with regard to the convenience of treatment administration. ${ }^{12,13}$

Chinese medicine (CM) has been used to manage respiratory diseases for thousands of years. Several Chinese herbal medicines have shown potential benefits for stable or acute exacerbations COPD in recent systematic reviews. ${ }^{14-16}$ Lung function, quality of life, and exercise capacity have also shown improvement by acupuncture and Tai Chi mind-body movement therapies. ${ }^{17,18}$ Multiple centers involved in randomized controlled trials have explored the clinical effects of the Chinese herbal formula, Yu Ping Feng granules and the single herb Ginseng for the treatment of COPD. ${ }^{19,20}$ The medical effects of CM therapies have been validated in an increasing number of clinical trials, to satisfy the need for evidence-based medicine. In addition to the evidence of therapeutic interventions, patient beliefs and preferences are powerful influences on the treatment effects in clinical practice. $^{21,22}$ Despite the increasing awareness in this area, the explicit consideration of patient values and preferences in clinical care remain limited. ${ }^{23,24}$ Information of patient attitudes regarding CM for COPD are unknown in terms of the transfer of evidence-based guidance to clinical practice. The aim of this pilot study was to investigate patient treatment preferences concerning CM and the feasibility for implementing a future larger scale survey.

\section{Methods}

\section{Study Design and Ethics Approval}

The pilot cross-section survey was performed to explore the understanding and perceptions of $\mathrm{CM}$ for the treatment of COPD. This study was conducted in accordance with the Declaration of Helsinki. This study was approved by the Ethics Committee of Guangdong Provincial Hospital of Chinese Medicine (GPHCM), Guangzhou, China (No. B2017-023-01), and all participants provided written informed consent before joining the study.

\section{Questionnaire Development}

The study-specific questionnaire was designed by methodologists, clinical experts on respiratory conditions, and nurses. The items were revised according to expert opinions to ensure clarity of questions, the main topics covered, and the validity of the questionnaire. A pre-test of the questionnaire was performed on five patients to ensure the feasibility of the survey administration modalities. First, the questionnaire was completed by individual patients without assistance. At the end of the survey, the respondents were asked which items were difficult to complete and whether they had additional questions or suggestions for improving the questionnaire. The questionnaire showed good reliability in terms of test-retesting outcomes among these patients. The correlation coefficient values were 0.987 . The final version consisted of 17 items, including basic characteristics, preferences for CM treatment options, patient-concerned outcomes, and importance of assessment of each treatment scenario. The factors related to each treatment scenario comprised seven items: the modality of prescription administration, results from clinical research, treatment reimbursement, side effects, additional costs, control of self-reported symptoms, and the clinicians' recommendation. The importance assessment was performed using a visual analogue scale (VAS) based on seven items. The linear scale was 10 centimeters long ranging in values from 0 to 10 , with anchor statements on the left "not important" and on the right "very important." The patients assessed importance with a mark on the scales according to their understanding of the survey question. The results were measured in centimeters starting from the left side by the researcher.

\section{Eligibility Criteria}

The participants were enrolled from patients attending a pulmonary clinic at GPHCM. Eligible patients were aged $\geq 18$ years, with a diagnosis of COPD based on GOLD criteria assessed by a clinical specialist. ${ }^{25}$ Patients judged as having the ability to understand the survey instructions and to communicate were included, while patients with evidence of mental illness, or those judged unable to cooperate or complete the survey were excluded. Thirty participants were expected to be included as the sample size to investigate the treatment preference of $\mathrm{CM}$. 
A senior specialist nurse received training in administering the questionnaires. The face-to-face survey was administered and explanations were given as necessary for any misunderstood items. However, the response by each patient was not influenced by the researcher.

\section{Statistical Analysis}

Data were entered into a database by a research assistant and were analyzed using descriptive statistics. Continuous variables were reported with mean (standard deviation) and categorical variables were presented as percentages. Nonparametric tests were performed to identify associations considering the limited final sample size. All analyses were conducted using PASW Statistics 18 software (SPSS Inc., Chicago, IL, USA).

\section{Results}

Thirty-five patients were recruited for the study from the Chronic Respiratory Disease Clinic of the GPHCM. Five participants declined interest in participating after receiving the study information; 30 patients completed the questionnaire. Most participants were male patients who willingly completed the survey, leading to a sex-difference among respondents ( 27 men vs 3 women). The age range of the respondents was from 55 to 88 years old, with the majority (90\%) having an educational background below high school level. Over half of the patients had experienced acute exacerbation of symptoms in the past, and one-third reported worsening symptoms in the past year. Patient characteristics are presented in Table 1. Most patients could complete the questionnaire within 10 minutes, only two reported difficulty in understanding the questions, but completed the survey within 20 minutes.

Two-thirds of patients preferred integrative Chinese and western medicines for the stable stage of COPD, followed by CM monotherapy (30\%). Compared with $\mathrm{CM}$ injections, Chinese patent medicines and CM decoction therapy were more popular choices for the respondents, which was probably due to the inconvenience associated with administration and adverse effects of the former. Several nonpharmacotherapies such as acupuncture, acupressure, point application, and Tai chi are encouraged in the management of COPD patients during the stable stage. The preferred scenario is point application, followed by Tai chi or Qigong and acupuncture. Almost a quarter of patients $(23.33 \%)$ claimed that they had improved lung function through physical exercises like running and deep breathing, excluding the above non-pharmacotherapies. Patients were mainly concerned
Table I Characteristics of the Participants

\begin{tabular}{|l|l|}
\hline Characteristic & $\begin{array}{l}\text { Number } \\
(\%)\end{array}$ \\
\hline $\begin{array}{l}\text { Sex } \\
\text { Male } \\
\text { Female }\end{array}$ & $\begin{array}{l}27(90.00) \\
3(10.00)\end{array}$ \\
\hline $\begin{array}{l}\text { Age, years } \\
\text { Mean } \pm \text { SD } \\
\text { Range }\end{array}$ & $68.97 \pm 8.27$ \\
\hline $\begin{array}{l}\text { Education } \\
\text { Middle school and below } \\
\text { High school } \\
\text { College }\end{array}$ & $55-88$ \\
\hline $\begin{array}{l}\text { Duration of COPD, years } \\
\text { Mean } \pm \text { SD } \\
\text { Range } \\
\text { Median }\end{array}$ & $14(46.67)$ \\
\hline $\begin{array}{l}\text { History of admission due to acute exacerbation of } \\
\text { symptoms } \\
\text { Yes }\end{array}$ & $13(43.33)$ \\
No & $3(10)$ \\
\hline History of admission due to acute exacerbation of \\
symptoms within the past year \\
Yes \\
No
\end{tabular}

Abbreviation: SD, standard deviation.

with the following clinical outcomes dyspnea, cough, sputum symptoms, and lung function, followed by exercise endurance such as walking distances, the frequency of acute exacerbations, and the length of hospital stay (Table 2).

Seven important attributes in the treatment scenarios were investigated. The most important factors assessed by respondents were clinicians' opinion, followed by side effects, and costs (Figure 1). Patients believed that clinicians would recommend the best treatment after considering all factors. There was significant attention to potential risks and the economic aspects of treatment scenarios for patients, while the survey showed that the modality of prescription administration was less important. Respondents selected the CM decoction with less consideration of inconvenience of administration if the treatment regimens showed superior effects. Although these factors were of lower importance for patients with a history of hospital admission, there were no significant differences with the exception of the convenience of treatment scenarios (Table 3). This difference should be addressed in a future survey. 
Table 2 Treatment Preference of Participants

\begin{tabular}{|l|l|}
\hline Characteristic & N (\%) \\
\hline $\begin{array}{l}\text { Treatment preference for whole healthcare system } \\
\text { Integrative medicine }\end{array}$ & $20(66.67)$ \\
Chinese medicine & $9(30)$ \\
Western medicine & $\mathrm{I}(3.33)$ \\
\hline Treatment preference for Chinese herbal medicine & \\
CM decoction & $12(40)$ \\
Chinese patent medicine & $18(60)$ \\
CM injections & $0(0)$ \\
\hline Treatment preference for CM non-pharmacotherapies & \\
Acupuncture & \\
Moxibustion & $7(23.33)$ \\
Point application & $4(13.33)$ \\
Cupping & $\mathrm{II}(36.67)$ \\
Tai chi/Qigong & $\mathrm{I}(3.33)$ \\
Other: exercise, deep breathing & $8(26.67)$ \\
\hline Concerned outcomes for participants & \\
Dyspnea, cough, sputum symptoms & $7(23.33)$ \\
Exercise tolerance & \\
Frequency of acute exacerbations & $22(73.33)$ \\
Length of hospital stay & $15(50)$ \\
Lung function & $7(23.33)$ \\
Laboratory examinations & $\mathrm{I}(3.33)$ \\
Other: mental state & $23(76.67)$ \\
\hline
\end{tabular}

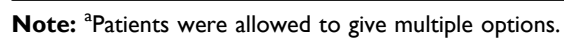

\section{Discussion}

This pilot study investigated treatment preferences and the importance of treatment attributes for the management of COPD patients using CM. Patients preferred to combine $\mathrm{CM}$ with western medicine for the treatment of COPD. In
Table 3 Comparison of Importance of Treatment Attributes According to History of Hospital Admission $(\bar{x} \pm S)$

\begin{tabular}{|l|l|l|l|}
\hline \multirow{2}{*}{ Attributes } & \multicolumn{2}{|l|}{$\begin{array}{l}\text { Experience of } \\
\text { Admission Due to } \\
\text { Acute Exacerbation } \\
\text { of Symptoms }\end{array}$} & \\
\cline { 2 - 3 } & $\begin{array}{l}\text { Yes } \\
(\mathbf{n}=17)\end{array}$ & $\begin{array}{l}\text { No } \\
(\mathbf{n}=13)\end{array}$ & \\
\hline Convenience of CM & $4.80 \pm 3.92$ & $8.07 \pm 2.30$ & 0.020 \\
administration & & & \\
Healthcare insurance is covered & $7.11 \pm 3.56$ & $8.42 \pm 1.68$ & 0.629 \\
Fewer side effects & $8.22 \pm 2.15$ & $9.29 \pm 0.55$ & 0.137 \\
Lower costs & $7.85 \pm 3.21$ & $9.45 \pm 0.40$ & 0.378 \\
Quicker symptom relief & $7.89 \pm 2.85$ & $9.33 \pm 0.43$ & 0.436 \\
Recommendation from clinicians & $8.74 \pm 2.03$ & $9.38 \pm 0.35$ & 0.449 \\
Efficacy reported from study & $6.54 \pm 3.24$ & $8.28 \pm 1.70$ & 0.116 \\
\hline
\end{tabular}

Note: * Mann-Whitney U-test was used.

addition, participants tended to prefer Chinese patent medicines and decoction over CM injections. We found that the outcomes most concerning patients were improvements in dyspnea, cough, sputum symptoms, and lung function. In addition, our results indicated that more rapid symptoms relief, lower costs, and fewer side effects were key attributes associated with the preferences of treatment options.

$\mathrm{CM}$ has been used to improve clinical outcomes of respiratory diseases in routine clinical practice, and especially symptoms associated with dyspnea and quality of life. Moreover, modern evidence has shown effectiveness and safety of $\mathrm{CM}$ in treating COPD. ${ }^{14-19}$ Therefore, integrative medicine was popular among

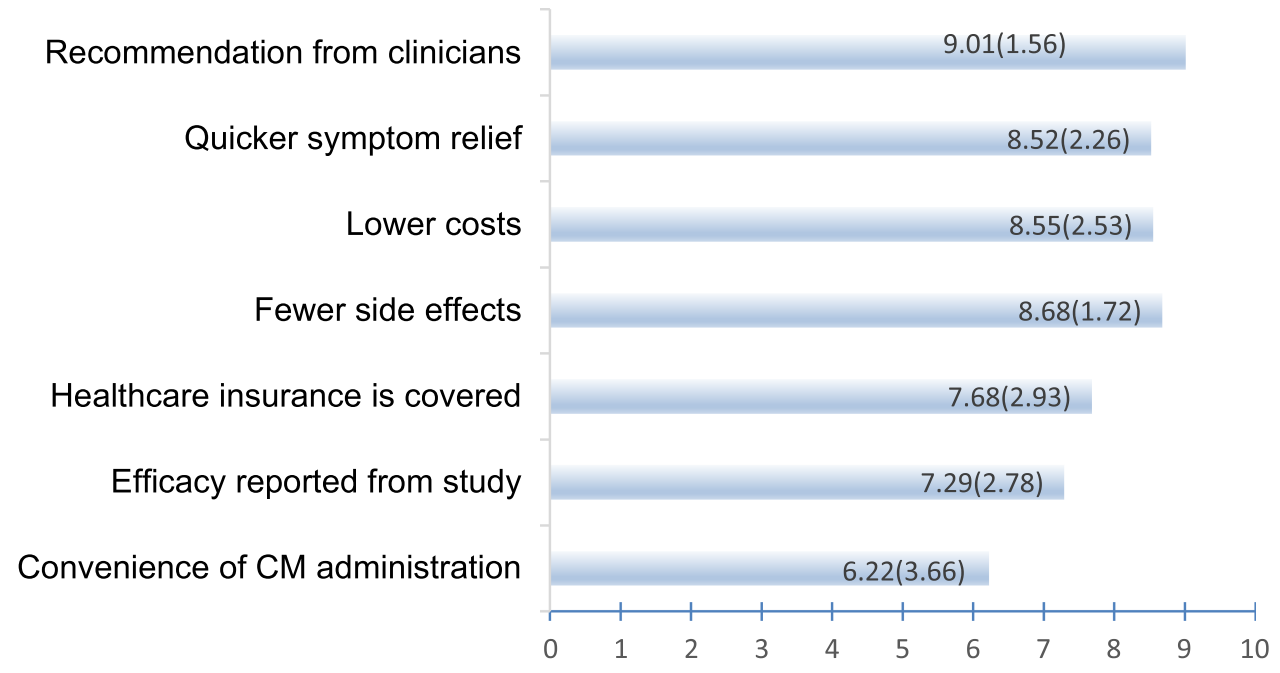

Figure I Importance estimation of treatment scenario attributes. The total score is 10 points. Mean score with standard deviation was showed for each item. 
participants in the study. Patients preferred oral CM for the treatment of COPD. This was probably due to higher risk of adverse reactions associated with $\mathrm{CM}$ injections, such as drug-induced anaphylaxis. ${ }^{26,27}$ The results showed that the symptoms of dyspnea, cough, and sputum were more important for patient perceptions. Patients described that they experienced negative effects on daily life activities with these unexpected symptoms. This effect actually reflected disease exacerbation, which was defined by acute changes in respiratory symptoms. ${ }^{25}$ However, the frequency of exacerbations was given less importance in this study. This distinction indicated that participants had limited knowledge of these clinical outcomes. Better explanation of the survey contents may be needed in the future study. Previous studies have also shown that the frequency of exacerbation was defined as a primary outcome to validate the efficacy of treatment remedies. ${ }^{28,29}$

Treatment efficacy and safety were commonly evaluated as important factors influencing the scenario preference. Cost was also highly valued for selection of treatment care. Even though China has attained remarkable achievements with regard to the primary health-care system and the national health insurance covers the costs of almost the entire Chinese population, there are still regional disparities among basic insurance schemes. ${ }^{30,31}$ Participants were mainly concerned with the reduction of out-of-pocket expenditures. The convenience of $\mathrm{CM}$ administration was considered to be less important, which is in contrast to previous studies for routine medication, ${ }^{9,12}$ but may be related to decoctions being a very popular administration modality in $\mathrm{CM}$ clinical practice since ancient times. It is generally believed that decoction may be more effective than other types of administration. However, a recent study showed that CM granules may have the same effectiveness as a decoction, although a definitive conclusion has not been reached due to the limitations of the included studies. ${ }^{32}$ Further exploration is still needed in this area. In our survey, the clinicians' recommendations played a large role in determining preference of treatment scenarios. Patients believe that physicians would prescribe the best available treatments after evaluating the balance of risks and benefits. Several studies have evaluated differences in perception between COPD patients and physicians. ${ }^{33-35}$ Patients need greater knowledge and power when addressing barriers in decision making. ${ }^{36}$

\section{Strengths and Limitations}

To our knowledge, this is the first study to investigate treatment preferences of patients with COPD for CM and may provide implications for defining future treatment strategies. This study provided the fundamental framework for future research, and indicated that qualitative studies are needed to explore valuable insight into patient perceptions.

Several limitations of our study should be considered. First, our study recruited a small sample size from a single care center institution with a background in $\mathrm{CM}$. The results may have led to bias and future studies should include a study sample with a greater variety of patients, for instance patients from a community center or from hospitals with a background in western medicine. Second, the findings were based on patients experiencing relatively stable disease status. This may have limited the generalizability of results to a broader population of COPD patients. Third, there is a significant sex difference among the survey respondents, although the prevalence of COPD is higher in men than in females in China. ${ }^{37,38}$ More female participants are expected to be included in the future survey.

\section{Future Research}

Further study with a larger sample size should recruit inpatients with acute exacerbation of symptoms to ensure more comprehensive results. Patients treated with "conventional" healthcare medicines, such as western medicine, are also expected to be included. Additional female respondents should be investigated, and if necessary, diverse sampling methods should be implemented to include multiple factors. Clinicians are interested in the patient perceptions with regard to specific interventions and in an evaluation of the clinical effect size, the certainty of evidence, and safety outcomes. Relevant results will promote the development and implementation of improved clinical practice guidelines. In order to better understand patient preferences, a mixedmethods study incorporating quantitative and qualitative tools is warranted to guarantee a more holistic approach.

\section{Conclusions}

In this pilot study, patients revealed their preference for Chinese medicine or $\mathrm{CM}$ decoctions over treatments by injection for the management of COPD. Evaluation of the attributes of different treatment scenarios indicated more rapid relief of symptoms and fewer side effects, which were rated of higher importance by patients together with the ease of use of CM prescriptions. Patients believed that 
CM combined with modern medications would achieve better improvement in clinical outcomes. Improvement of dyspnea, cough, sputum symptoms, and lung function are the primary clinical outcomes that concern patients and should be taken into account by practitioners in clinical practice. The small sample size of this pilot study limits the generalizability of the findings. Further research with larger sample sizes evaluating patient preferences for specified CM remedies is needed. A comprehensive mixed methods approach involving quantitative and qualitative data collection is to be implemented before any definitive conclusions can be made.

\section{Abbreviations}

COPD, chronic obstructive pulmonary disease; CM, Chinese medicine; GPHCM, Guangdong Provincial Hospital of Chinese Medicine; VAS, visual analogue scale; SD, standard deviation.

\section{Acknowledgments}

We would like to thank Yongwen Li and Zeying Huang of pulmonary clinic for the enrollment and management of participants.

\section{Funding}

The project was supported by a grant from the National Key R\&D Program of China (Grant No. 2019YFC1709804), the Specific Research Fund for TCM Science and Technology of Guangdong Provincial Hospital of Chinese Medicine (grant no. YN2019QL16) and Guangzhou Science and Technology Planning Project (grant no. 202002020042). Support was also received from the China-Australia International Research Centre for Chinese Medicine, funded by the Guangdong Provincial Academy of Chinese Medical Sciences and Guangdong Provincial Hospital of Chinese Medicine, Guangdong, China, and RMIT University, Australia.

\section{Disclosure}

All authors declare that they have no competing interests.

\section{References}

1. Rogliani P, Ora J, Puxeddu E, Matera MG, Cazzola M. Adherence to copd treatment: myth and reality. Respir Med. 2017;129:117-123. doi:10.1016/j.rmed.2017.06.007

2. Bender BG. Nonadherence in chronic obstructive pulmonary disease patients: what do we know and what should we do next? Curr Opin Pulm Med. 2014;20(2):132-137. doi:10.1097/MCP.000000000000 0027
3. Haupt D, Krigsman K, Nilsson JL. Medication persistence among patients with asthma/copd drugs. Pharm World Sci. 2008;30 (5):509-514. doi:10.1007/s11096-008-9197-4

4. Restrepo RD, Alvarez MT, Wittnebel LD, et al. Medication adherence issues in patients treated for copd. Int J Chron Obstruct Pulmon Dis. 2008;3(3):371-384. doi:10.2147/COPD.S3036

5. Bourbeau J, Bartlett SJ. Patient adherence in copd. Thorax. 2008;63 (9):831-838. doi:10.1136/thx.2007.086041

6. George J, Kong DC, Thoman R, Stewart K. Factors associated with medication nonadherence in patients with copd. Chest. 2005;128 (5):3198-3204. doi:10.1378/chest.128.5.3198

7. Guyatt G, Rennie D, Meade MO, Deborah J. Cook. Users'guides to the Medical Literature: A Manual for Evidence-Based Clinical Practice. 3rd ed. New York: McGraw Hill Education \& The JAMA Network; 2015.

8. Blinman P, King M, Norman R, Viney R, Stockler MR. Preferences for cancer treatments: an overview of methods and applications in oncology. Ann Oncol. 2012;23(5):1104-1110. doi:10.1093/annonc/ mdr559

9. Kawata AK, Kleinman L, Harding G, Ramachandran S. Evaluation of patient preference and willingness to pay for attributes of maintenance medication for chronic obstructive pulmonary disease (copd). patient. 2014;7(4):413-426. doi:10.1007/s40271-014-0064-1

10. Miravitlles M, Anzueto A, Legnani D, Forstmeier L, Fargel M. Patient's perception of exacerbations of copd-the perceive study. Respir Med. 2007;101(3):453-460. doi:10.1016/j.rmed.2006.07.010

11. Utens CM, Goossens LM, van Schayck OC, et al. Patient preference and satisfaction in hospital-at-home and usual hospital care for copd exacerbations: results of a randomised controlled trial. Int $J$ Nurs Stud. 2013;50(11):1537-1549. doi:10.1016/j.ijnurstu.2013.03.006

12. O'Hagan P, Dederichs J, Viswanad B, Gasser M, Walda S. Patient preference for a maintenance inhaler in chronic obstructive pulmonary disease: a comparison of breezhaler and respimat. $J$ Thorac Dis. 2018;10(10):5727-5735. doi:10.21037/jtd.2018.09.126

13. Chouaid C, Germain N, De Pouvourville G, et al. Patient preference for chronic obstructive pulmonary disease (copd) treatment inhalers: a discrete choice experiment in france. Curr Med Res Opin. 2019;35 (5):785-792. doi:10.1080/03007995.2019.1574507

14. Liu S, Shergis J, Chen X, et al. Chinese herbal medicine (weijing decoction) combined with pharmacotherapy for the treatment of acute exacerbations of chronic obstructive pulmonary disease. Evid Based Complement Alternat Med. 2014;2014:257012. doi:10.1155/2014/ 257012

15. Chen Y, Shergis JL, Wu L, et al. A systematic review and meta-analysis of the herbal formula Buzhong Yiqi Tang for stable chronic obstructive pulmonary disease. Complement Ther Med. 2016;29:94-108. doi:10.1016/j.ctim.2016.09.017

16. Chen X, May B, Di YM, et al. Oral Chinese herbal medicine combined with pharmacotherapy for stable COPD: a systematic review of effect on BODE index and six minute walk test. PLoS One. 2014;9 (3):e91830. doi:10.1371/journal.pone.0091830

17. Coyle ME, Shergis JL, Huang ET, et al. Acupuncture therapies for chronic obstructive pulmonary disease: a systematic review of randomized, controlled trials. Altern Ther Health Med. 2014;20 (6): 10-23.

18. Guo C, Xiang G, Xie L, et al. Effects of Tai Chi training on the physical and mental health status in patients with chronic obstructive pulmonary disease: a systematic review and meta-analysis. $J$ Thorac Dis. 2020;12(3):504-521. doi:10.21037/jtd.2020.01.03

19. Ma J, Zheng J, Zhong N, et al. Effects of yupingfeng granules on acute exacerbations of copd: a randomized, placebo-controlled study. Int J Chron Obstruct Pulmon Dis. 2018;13:3107-3114. doi:10.2147/ COPD.S170555

20. Shergis JL, Thien F, Worsnop CJ, et al. 12-month randomised controlled trial of ginseng extract for moderate COPD. Thorax. 2019;74 (6):539-545. doi:10.1136/thoraxjnl-2018-212665 
21. Preference Collaborative Review Group. Patients' preferences within randomised trials: systematic review and patient level meta-analysis. BMJ. 2008;337:a1864. doi:10.1136/bmj.a1864

22. Thomas E, Croft PR, Paterson SM, Dziedzic K, Hay EM. What influences participants' treatment preference and can it influence outcome? Results from a primary care-based randomised trial for shoulder pain. Br J Gen Pract. 2004;54(499):93-96.

23. Zhang Y, Tikkinen KAO, Agoritsas T, et al. Patients' values and preferences of the expected efficacy of hip arthroscopy for osteoarthritis: a protocol for a multinational structured interview-based study combined with a randomised survey on the optimal amount of information to elicit preferences. BMJ Open. 2014;4(10):e005536. doi:10.1136/bmjopen-2014-005536

24. van der Weijden T, Légaré F, Boivin A, et al. How to integrate individual patient values and preferences in clinical practice guidelines? A research protocol. Implement Sci. 2010;5:10. doi:10.1186/ 1748-5908-5-10

25. Global strategy for the diagnosis, management and prevention of copd, global initiative for chronic obstructive lung disease (gold); 2020. Available from: https://goldcopd.org/gold-reports/. Accessed March 2, 2021

26. Li X, Thai S, Lu W, et al. Traditional chinese medicine and drug-induced anaphylaxis: data from the beijing pharmacovigilance database. Int J Clin Pharm. 2018;40(4):921-927. doi:10.1007/ s11096-018-0699-4

27. Yi Y, Li CY, Zhao Y, et al. Safety of animal traditional chinese medicine (tcm) injections. Zhongguo Zhong Yao Za Zhi. 2018;43 (22):4391-4396. doi:10.19540/j.cnki.cjcmm.20180711.001

28. Devereux G, Cotton S, Fielding S, et al. Effect of theophylline as adjunct to inhaled corticosteroids on exacerbations in patients with copd: a randomized clinical trial. JAMA. 2018;320(15):1548-1559. doi:10.1001/jama.2018.14432

29. Poole P, Sathananthan K, Fortescue R. Mucolytic agents versus placebo for chronic bronchitis or chronic obstructive pulmonary disease. Cochrane Database Syst Rev. 2019;5(5):CD001287. doi:10.1002/14651858.CD001287.pub6
30. Li X, Lu J, Hu S, et al. The primary health-care system in china. Lancet. 2017;390(10112):2584-2594. doi:10.1016/S0140-6736(17) 33109-4

31. Dou G, Wang Q, Ying X. Reducing the medical economic burden of health insurance in china: achievements and challenges. Biosci Trends. 2018;12(3):215-219. doi:10.5582/bst.2018.01054

32. Luo H, Li Q, Flower A, Lewith G, Liu J. Comparison of effectiveness and safety between granules and decoction of chinese herbal medicine: a systematic review of randomized clinical trials $J$ Ethnopharmacol. 2012;140(3):555-567. doi:10.1016/j.jep.2012. 01.031

33. Celli B, Blasi F, Gaga M, et al. Perception of symptoms and quality of life - comparison of patients' and physicians' views in the copd mirror study. Int J Chron Obstruct Pulmon Dis. 2017;12:2189-2196. doi:10.2147/COPD.S136711

34. Miravitlles M, Ferrer J, Baró E, Lleonart M, Galera J. Differences between physician and patient in the perception of symptoms and their severity in copd. Respir Med. 2013;107(12):1977-1985. doi:10.1016/j.rmed.2013.06.019

35. Hernandez P, Balter MS, Bourbeau J, Chan CK, Marciniuk DD, Walker SL. Canadian practice assessment in chronic obstructive pulmonary disease: respiratory specialist physician perception versus patient reality. Can Respir J. 2013;20(2):97-105. doi:10.1155/2013/ 369019

36. Joseph-Williams N, Elwyn G, Edwards A. Knowledge is not power for patients: a systematic review and thematic synthesis of patient-reported barriers and facilitators to shared decision making. Patient Educ Couns. 2014;94(3):291-309. doi:10.1016/j.pec.2013. 10.031

37. Fang L, Gao P, Bao H, et al. Chronic obstructive pulmonary disease in China: a nationwide prevalence study. Lancet Respir Med. 2018;6 (6):421-430. doi:10.1016/S2213-2600(18)30103-6

38. Wang $\mathrm{C}, \mathrm{Xu} \mathrm{J}$, Yang L, et al. Prevalence and risk factors of chronic obstructive pulmonary disease in China (the China Pulmonary Health [CPH] study): a national cross-sectional study. Lancet. 2018;391 (10131):1706-1717. doi:10.1016/S0140-6736(18)30841-9
Patient Preference and Adherence

\section{Publish your work in this journal}

Patient Preference and Adherence is an international, peer-reviewed, open access journal that focusing on the growing importance of patient preference and adherence throughout the therapeutic continuum. Patient satisfaction, acceptability, quality of life, compliance, persistence and their role in developing new therapeutic modalities and compounds to optimize clinical outcomes for existing disease states are major areas of interest for the journal. This journal has been accepted for indexing on PubMed Central. The manuscript management system is completely online and includes a very quick and fair peer-review system, which is all easy to use. Visit http:/ www.dovepress.com/testimonials.php to read real quotes from published authors. 